Research Article

\title{
Prediction of Intraformational Remaining Oil Distribution Based on Reservoir Heterogeneity: Application to the J-Field
}

\author{
Jie Zhang, ${ }^{1}$ Feifei Fang $\left({ }^{2},{ }^{2}\right.$ Jie Wang, ${ }^{2}$ Yajie Tian, ${ }^{3}$ Fei Mo, ${ }^{2}$ Qi Li, ${ }^{1}$ Sainan $\mathrm{Li}^{2}$ \\ Xiaoliang Huang, ${ }^{2}$ and Yi Yang ${ }^{1}$ \\ ${ }^{1}$ Institute of Porous Flow and Fluid Mechanics, University of Chinese Academy of Sciences, Langfang 065007, China \\ ${ }^{2}$ School of Petroleum Engineering, Chongqing University of Science \& Technology, Chongqing 401331, China \\ ${ }^{3}$ Oil Field Development Research Institute, Research Institute of Petroleum Exploration and Development, PetroChina, \\ Beijing 100089, China
}

Correspondence should be addressed to Feifei Fang; fangfeifei@cqust.edu.cn

Received 30 June 2020; Revised 28 January 2021; Accepted 12 March 2021; Published 31 March 2021

Academic Editor: Xuemei Liu

Copyright (C) 2021 Jie Zhang et al. This is an open access article distributed under the Creative Commons Attribution License, which permits unrestricted use, distribution, and reproduction in any medium, provided the original work is properly cited.

\begin{abstract}
At high water cut stage, the study of remaining oil distribution in water-flooding reservoir is the basis of implementing potentialtapping measures and enhancing oil recovery. At present, most of the oilfields in China have entered the stage of ultrahigh water cut. The reserves of the oilfields are highly developed, the situation of water flooding is extremely complex, and it is difficult to predict the distribution of the remaining oil, which seriously restricts the adjustment of the production measures, tapping the potential and improving the ultimate recovery rate. In view of aforementioned difficulties, this study puts forward a research approach to predict remaining oil distribution based on reservoir heterogeneity, which can quantitatively characterize reservoir heterogeneity. In order to avoid the drawback that a single parameter cannot fully describe the characteristics of pore structure, the composite index of pore structure $(\mathrm{SQRT}(\mathrm{K} / \Phi))$ is introduced to study the pore microstructure. The composite index of pore structure is used to predict the distribution of remaining oil in the formation, and the results are basically consistent with those calculated by numerical simulation. It is concluded that the larger the fractal dimension of the composite index of pore structure is, the stronger the heterogeneity of reservoir is; the smaller the composite index of pore structure is, the smaller the recovery degree is. The composite index of pore structure is used to analyze and predict the distribution of remaining oil in the layer, which provides a new direction for the prediction method of remaining oil.
\end{abstract}

\section{Introduction}

At present, the development of the main oilfields in China mostly enters the stage of high water cut stage, the distribution of underground fluid is becoming more and more complex, and the exploitation is becoming increasingly challenging. Therefore, it is of great significance to know exactly the remaining oil reserves and their distribution for the adjustment of the production measures, potential tapping, and ultimate recovery enhancement of the oilfield, and it is also an important means to realize the development strategy of "water control and oil stabilization" [1].

In recent years, although the method of remaining oil description has developed rapidly, most of them are qualitative description except numerical simulation method, and the further development of this technology is hindered by the degree of popularization, the depth of research, and the high cost of testing [2]. Present research on remaining oil mainly focuses on the following three aspects: (1) remaining oil distribution and characteristic study [3], (2) measuring and monitoring study on remaining oil saturation (ROS) [4], and (3) potential-tapping technology study [5].

Because of the complexity of oil-water relationship of the reservoir in the high water cut stage, it is more difficult to study the distribution of remaining oil. It is inevitable to have great limitations to predict the distribution of remaining oil based on a single subject. Therefore, only the application of multidisciplinary theory, method, and 
technology can accurately predict the distribution of remaining oil.

The manifested evidences suggest that interlayer heterogeneity, interior-layer heterogeneity, and plane heterogeneity have an effect on the remaining oil distribution [6]. Because of the difference of heterogeneity in the reservoir layer, the water drive effect of different microfacies in the vertical direction is different, and the distribution of remaining oil is uneven and concentrated in the strongly heterogeneous region. Influenced by the heterogeneity of reservoir layers, the remaining oil is usually concentrated in the single layer with large permeability range and poor physical properties. In the plane, restricted by the distribution, scale, connectivity, and spatial combination of sand bodies, the microfacies with relatively poor physical properties and large permeability range in the reservoir are also the main enrichment areas and potential exploration targets of remaining oil.

Webber puts forward the classification system of quantitative recognition of heterogeneity in the stage of oilfield evaluation and development [7]. Considering heterogeneity and its influence on fluid flow, reservoir heterogeneity is divided into seven types: closed or semiclosed or unclosed fault, unit boundary, permeable layer in unit, interlayer in unit, lamination or cross bedding, micro-heterogeneity, and closed or open fracture. Daws and Prosser proposed to divide reservoir heterogeneity into five grades from large to small: sedimentary strata, sedimentary facies, boundary/bedding, lamination, and diagenesis [8]. According to the characteristics of continental reservoirs and production practice, Qiu et al. put forward a classification scheme to study reservoir heterogeneity from interlayers and interior layers, plane, and microlevel [9]. In addition, there are some effective methods for studying reservoir heterogeneity that uses dynamic-based indicators such as tracers and local grid refinement and downscaling [10-13].

The heterogeneity of oil and gas reservoir is not only the main factor to control oil and gas accumulation but also the basis of remaining oil distribution research $[14,15]$. With the increasingly severe exploitation situation of major oil fields and the deepening understanding of the importance of remaining oil exploration, the research on reservoir heterogeneity has been deepened and developed, and the research contents and methods have been improved and enriched.

According to the present situation of oil and gas field development in China, the relationship between reservoir heterogeneity and remaining oil distribution is discussed by studying reservoir heterogeneity. We introduce the parameter of the composite index of pore structure and apply it to the study of the heterogeneity in the macroscopic layer. The composite index of pore structure can accurately represent not only the characteristics of micropore structure but also the degree of heterogeneity in the reservoir, which is a kind of parameter connecting the micro- and macrodescription. Based on this, the composite index of the pore structure combined with the numerical simulation method is proposed to analyze and predict the distribution of remaining oil.

\section{Quantitative Characterization of Reservoir Heterogeneity}

According to the reservoir classification scheme put forward by Qiu and Chen [9], reservoir heterogeneity is classified into interlayer heterogeneity, plane heterogeneity, interiorlayer heterogeneity, and pore heterogeneity. Interlayer heterogeneity includes the rhythmicity of rock granularity, the sequence of bedding structure, the permeability difference and the location of high permeability section, the distribution frequency and size of discontinuous thin shale in the layer, the distribution of other impermeable interlayer, and the ratio of vertical permeability. Pore heterogeneity mainly refers to the heterogeneity of micropore structure, including sand body pore, throat size and its uniformity, configuration, and connectivity of pore throat. In this paper, the quantitative characterization of heterogeneity of the study area is described from a macroperspective.

2.1. Geological Characteristics. The study area is about $25 \mathrm{~km}$ east of " $\mathrm{K}$ " City, which is located in a reverse fault zone in the northwest margin of " $\mathrm{J}$ " basin. The north, southeast, and west are, respectively, bounded by faults. The faults in the north act as the function of blocking the reservoir. The study area is a structural-lithological reservoir blocked by faults (Figure 1).

In general, the study area is a NW-SE structural reservoir blocked by faults, with a dip angle of 2-30, and the depth of the middle part of the reservoir is $1340 \mathrm{~m}$. The block is formed by three faults.

Sedimentary microfacies can be divided into three subfacies: fan root, fan subfacies, and fan margin. Among them, fan root subfacies mainly develop braided channel microfacies, fan subfacies mainly develop braided channel and slow flow sand microfacies, and fan margin mainly develops overland mud microfacies.

The " $\mathrm{K}$ " formation in the study area is unconformity deposited on the carboniferous reservoir, and the upper layer is successively deposited by the Baijiantan formation $\left(T_{3} b\right)$, Badaowan Formation in Jurassic System $\left(J_{1} b\right)$, Sangonghe Formation $\left(J_{1} s\right)$, Xishanyao Formation $\left(J_{2} \mathrm{x}\right)$, Toutunhe Formation $\left(J_{2} t\right)$, Qigu formation $\left(J_{3} q\right)$, and Tugulu group (K1t) of Cretaceous System. The study area is $\mathrm{K}_{7}$ sand formation, and $\mathrm{K}_{7}$ sand consists of four layers $\mathrm{K}_{7}{ }^{1}, \mathrm{~K}_{7}{ }^{2}, \mathrm{~K}_{7}{ }^{3}$, and $\mathrm{K}_{7}{ }^{4}$ and is subdivided into nine layers $\mathrm{K}_{7}{ }^{1}, \mathrm{~K}_{7}{ }^{2-1}, \mathrm{~K}_{7}{ }^{2-2}$, $\mathrm{K}_{7}^{2-3}, \mathrm{~K}_{7}^{3-1}, \mathrm{~K}_{7}^{3-2}, \mathrm{~K}_{7}^{3-3}, \mathrm{~K}_{7}^{4-1}$, and $\mathrm{K}_{7}^{4-2}$. The main oil layers are $\mathrm{K}_{7}^{2}, \mathrm{~K}_{7}^{3}$, and $\mathrm{K}_{7}^{4}$.

2.2. Study on the Heterogeneity of Permeability in Layers. The heterogeneity in a single sand layer refers to the change of its internal vertical reservoir properties, including the change of permeability in the vertical layer. The variation range of porosity of $\mathrm{K}_{7}$ sand group in the study area is mainly from $12 \%-16 \%$, and the variation range of permeability is $8 \times 10^{-3} \mu \mathrm{m}^{2}-17 \times 10^{-3} \mu \mathrm{m}^{2}$. According to the results of stratigraphic division, $K_{7}$ sand consists of four layers $K_{7}{ }^{1}$, $\mathrm{K}_{7}{ }^{2}, \mathrm{~K}_{7}{ }^{3}$, and $\mathrm{K}_{7}^{4}$ and is subdivided into nine layers $\mathrm{K}_{7}{ }^{1}$, $\mathrm{K}_{7}{ }^{2-1}, \mathrm{~K}_{7}{ }^{2-2}, \mathrm{~K}_{7}{ }^{2-3}, \mathrm{~K}_{7}{ }^{3-1}, \mathrm{~K}_{7}{ }^{3-2}, \mathrm{~K}_{7}{ }^{3-3}, \mathrm{~K}_{7}^{4-1}$, and $\mathrm{K}_{7}^{4-2}$. 


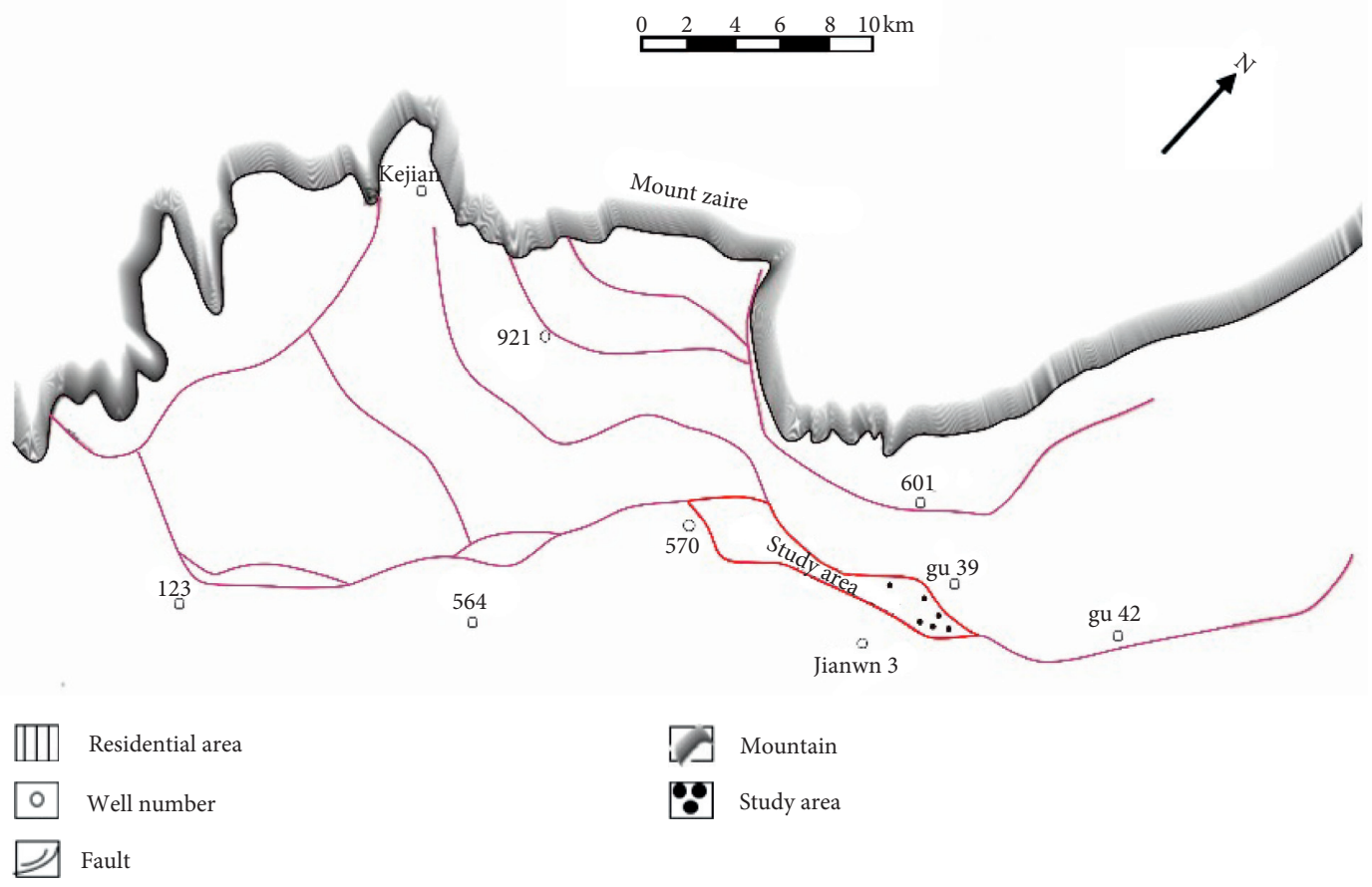

Figure 1: Location map of the study area.

The permeability heterogeneity parameters of each sublayer are shown in Table 1.

The analysis of permeability heterogeneity shows that porosity and permeability have little change, and the heterogeneity in the layer is weak. In general, the average permeability difference of each small layer in $\mathrm{K}_{7}$ sand formation is small, and the heterogeneity is not strong [2].

Generally speaking, the larger the $V_{k}, T_{k}$, and $J_{k}$, the stronger the reservoir heterogeneity, otherwise weaker. The classification standard of the heterogeneity of clastic rock reservoir in China mainly adopts the standard issued by China National Petroleum Corporation (CNPC), as shown in Table 2.

According to Table 2, we judged that the heterogeneity type in $K_{7}$ sand group is a relatively homogeneous type. Permeability contour map of $\mathrm{K}_{7}$ sand formation is shown in Figure 2. It can be seen that the plane permeability is also relatively uniform, mainly concentrated in $10 \sim 18 \mathrm{mD}$.

\subsection{Study on Heterogeneity in Layers with Pore Structure} Index. The size and distribution of pore radius can be roughly reflected by the pressure and saturation of mercury withdrawal $[16,17]$. It is not only a function of pore throat radius distribution and pore volume but also a function of porosity, permeability, and saturation. The quantitative characteristic parameters of capillary pressure curve, which can characterize the pore structure of reservoir, mainly include displacement pressure, saturation median pressure and median radius, maximum mercury saturation, and efficiency of mercury withdrawal, which are the important basis to reflect the microheterogeneity of the reservoir. Mercury injection data of $\mathrm{K}_{7}{ }^{1}, \mathrm{~K}_{7}{ }^{2}, \mathrm{~K}_{7}{ }^{3}$, and $\mathrm{K}_{7}{ }^{4}$ are collected, as shown in Figure 3.
According to the mercury injection data of each layer, the curves of the $\mathrm{K}_{7}{ }^{4}$ layer are similar, which proves that the pore structure of the rock samples taken from the $\mathrm{K}_{7}{ }^{4}$ layer is similar. After analysis and comparison, we conclude that the heterogeneity of four small layers is gradually weakened.

The composite index of the pore structure in four layers of $\mathrm{K}_{7}$ sand group is used to study the reservoir heterogeneity, which can truly reflect the pore structure characteristics of samples. Using geological model data to calculate the frequency distribution of composite index of pore structure of each layer, it can be seen from Figure 4 that the heterogeneity in layer $\mathrm{K}_{7}{ }^{1}$ is strong, and the index is widely changed between $0.5 \sim 2.5$ as can be seen from Figure 4(a). The heterogeneity in layer $\mathrm{K}_{7}^{4}$ is relatively weak, and the index is mainly changed between $0.5 \sim 1.5$ as can be seen from Figure 4(d).

It is generally believed that the fractal dimension of SQRT $(K / \Phi)$ in three-dimensional Euclidean space is mostly in the range of $2-3[18,19]$. The closer the fractal dimension is to 2 , the weaker the heterogeneity is and the better the reservoir capability is. The closer the fractal dimension is to 3 , the rougher the pore throat surface is, the worse the reservoir capability is, and the stronger the heterogeneity of the reservoir is [20]. We used the core data to analyze the fractal dimension of the composite index of pore structure SQRT $(K / \Phi)$ in the layer, as shown in Figure 5. The fractal dimension of the $\mathrm{K}_{7}{ }^{1}$ layer is 2.88 , that of the $\mathrm{K}_{7}{ }^{2}$ layer is 2.74 , that of the $\mathrm{K}_{7}^{3}$ layer is 2.73 , and that of the $\mathrm{K}_{7}^{4}$ layer is 2.38 . The fractal dimension of the $\mathrm{K}_{7}{ }^{1}$ layer is the largest, so the heterogeneity in the layer is relatively the strongest. At the same time, the fractal dimension of the $\mathrm{K}_{7}^{4}$ layer is the smallest, and the heterogeneity in the layer is also the smallest. We conclude that, from the $\mathrm{K}_{7}{ }^{1}$ layer to $\mathrm{K}_{7}{ }^{4}$ layer, the heterogeneity in the reservoir is gradually weakened. 
TABLE 1: The permeability heterogeneity parameters of each sublayer of the $K_{7}$ layer.

\begin{tabular}{|c|c|c|c|c|c|c|}
\hline \multirow{2}{*}{ Block } & \multirow{2}{*}{ Layer } & \multicolumn{2}{|c|}{ Permeability $\left(10^{-3} \mu \mathrm{m}^{2}\right)$} & \multirow{2}{*}{ Variation coefficient $\left(V_{k}\right)$} & \multirow{2}{*}{ Burst coefficient $\left(T_{k}\right)$} & \multirow{2}{*}{ Permeability gradation $\left(J_{k}\right)$} \\
\hline & & Range & Average & & & \\
\hline \multirow{12}{*}{$\mathrm{K}_{7}$} & $\mathrm{~K}_{7}^{1}$ & $3.8313-43.2000$ & 22.7584 & 0.6166 & 1.8982 & 11.2756 \\
\hline & $\mathrm{K}_{7}^{2-1}$ & $0.3533-7.4757$ & 4.1618 & 0.9424 & 1.7962 & 21.1602 \\
\hline & $\mathrm{K}_{7}^{2-2}$ & $0.6865-5.0456$ & 2.6822 & 0.5932 & 1.8811 & 7.3494 \\
\hline & $\mathrm{S}_{7}^{2-3}$ & $0.7506-8.7576$ & 3.7820 & 0.7960 & 2.3156 & 11.6672 \\
\hline & & $7^{2}$ average & 3.5420 & 0.7772 & 1.9977 & 13.3922 \\
\hline & $\mathrm{K}_{7}^{3-1}$ & $0.2388-2.7038$ & 1.4235 & 0.6536 & 1.8994 & 11.3248 \\
\hline & $\mathrm{K}_{7}^{3-2}$ & $1.2870-5.3963$ & 3.0085 & 0.4900 & 1.7937 & 4.1929 \\
\hline & $\mathrm{K}_{7}^{3-3}$ & $0.7770-10.2210$ & 3.2202 & 0.8251 & 3.1740 & 13.1533 \\
\hline & & $7^{3}$ average & 2.5507 & 0.6562 & 2.2890 & 9.5570 \\
\hline & $\mathrm{K}_{7}^{4-1}$ & $0.4665-3.3899$ & 1.7474 & 0.5345 & 1.9399 & 7.2660 \\
\hline & $\mathrm{K}_{7}^{4-2}$ & $0.2000-1.0070$ & 0.5188 & 0.5343 & 1.9410 & 5.0350 \\
\hline & & 7 average & 1.1331 & 0.5344 & 1.9405 & 6.1505 \\
\hline
\end{tabular}

TABLe 2: Division standard of reservoir heterogeneity.

\begin{tabular}{lccc}
\hline Type & Variation coefficient $\left(V_{k}\right)$ & Burst coefficient $\left(T_{k}\right)$ & Permeability gradation $\left(J_{k}\right)$ \\
\hline Homogeneous type & $<0.5$ & $<2$ & $<2$ \\
Relatively homogeneous & $0.5 \sim 0.7$ & $2 \sim 3$ & $2 \sim 6$ \\
Heterogeneous type & $>0.7$ & $>3$ & $>6$ \\
\hline
\end{tabular}

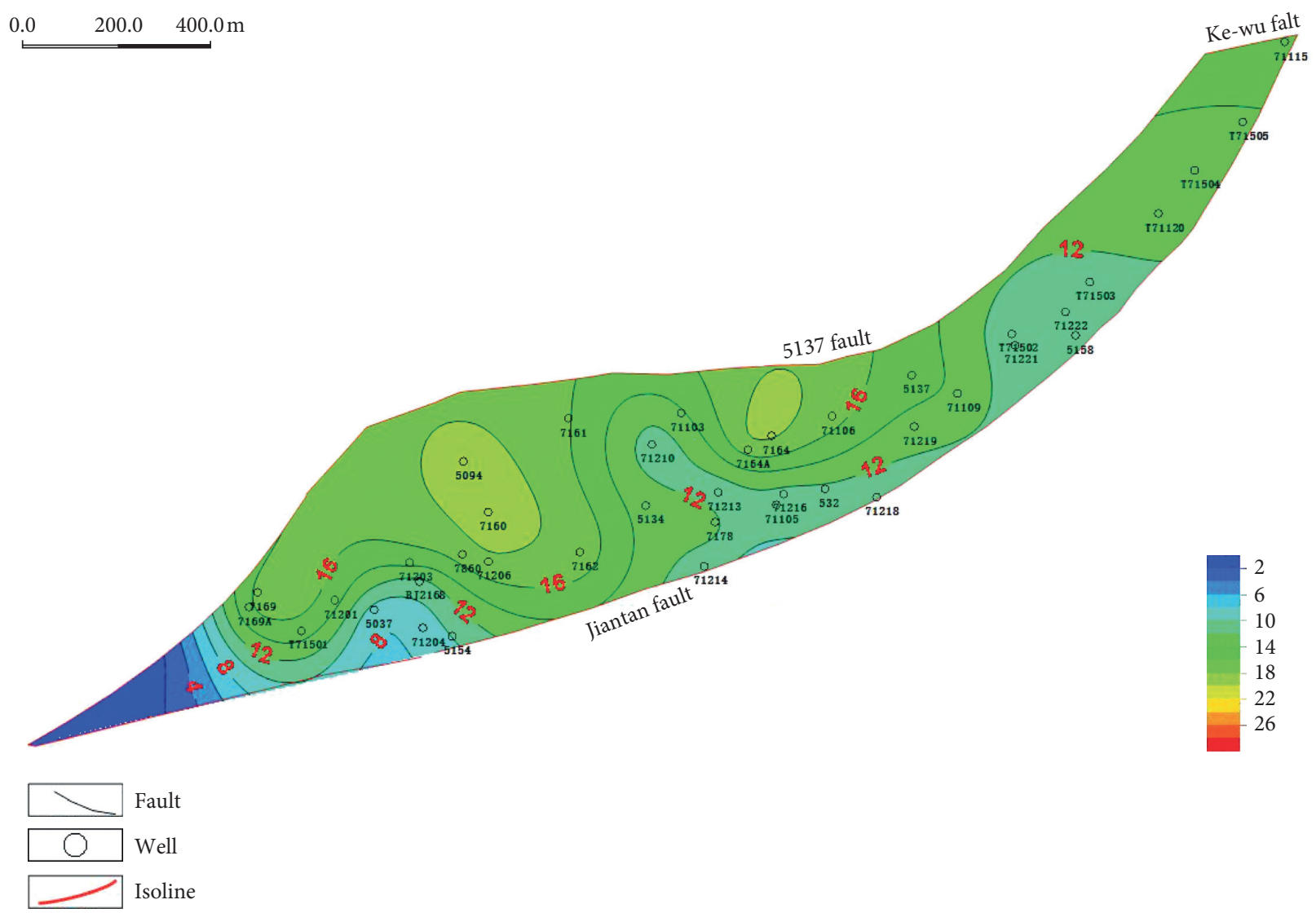

Figure 2: Permeability contour map of $\mathrm{K}_{7}$ sand formation.

The intraformational heterogeneity obtained by using the frequency distribution of the composite index of the pore structure calculated by the geological model data is consistent with the intraformational heterogeneity obtained by using the core data to analyze the interlayer's composite index of pore structure. The larger the fractal dimension of 


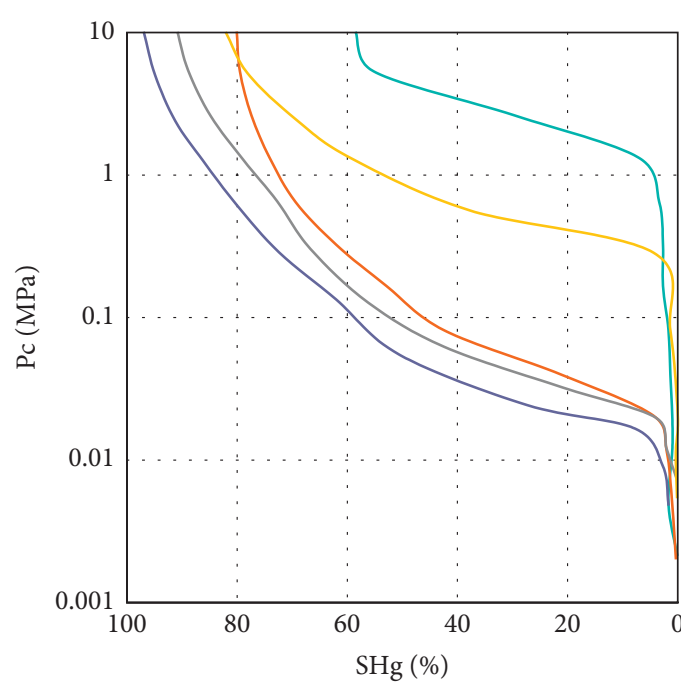

(a)

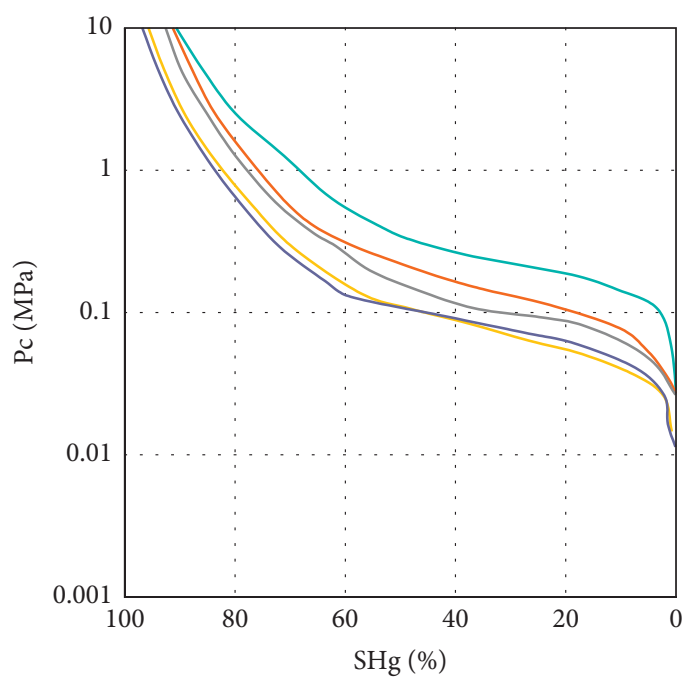

(c)

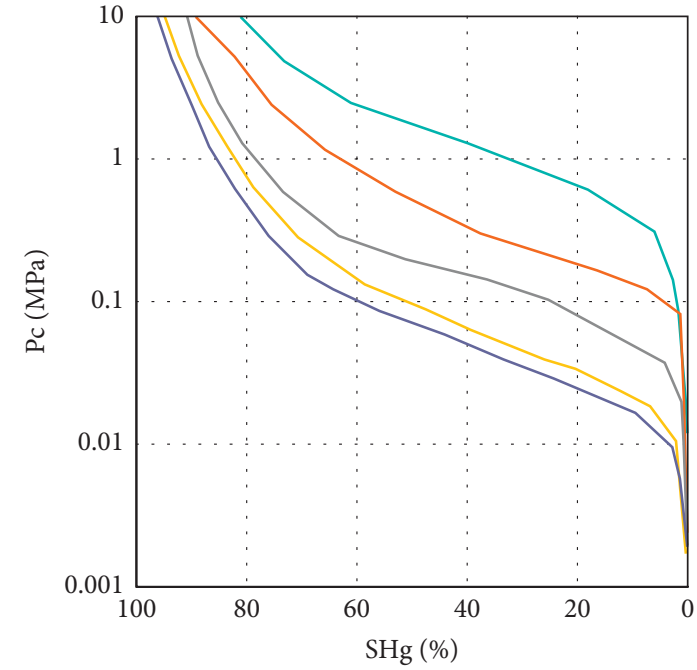

(b)

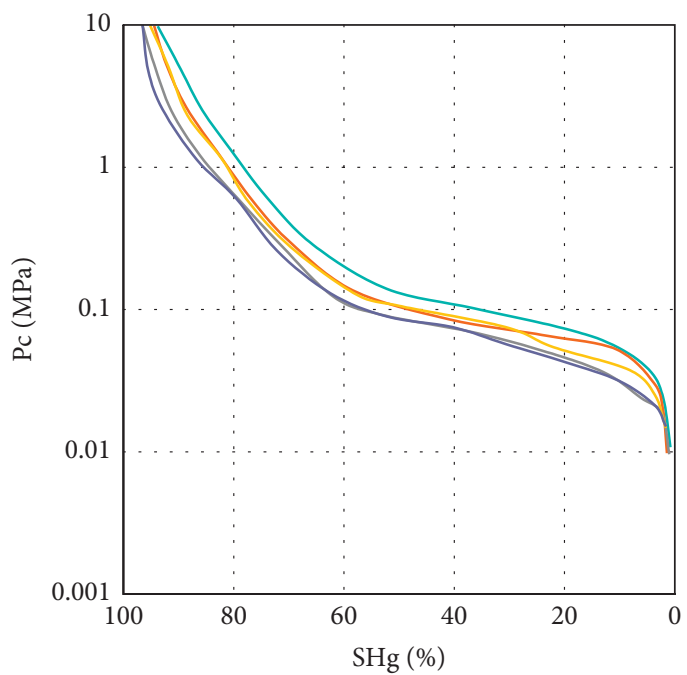

(d)

Figure 3: Mean capillary pressure curve. (a) $\mathrm{K}_{7}{ }^{1}$. (b) $\mathrm{K}_{7}{ }^{2}$. (c) $\mathrm{K}_{7}{ }^{3}$. (d) $\mathrm{K}_{7}^{4}$.

$\mathrm{SQRT}(\mathrm{K} / \Phi)$ is, the stronger the heterogeneity is. The composite index of the pore structure can well reflect the heterogeneity in the layer.

\section{Study on the Distribution Law of Remaining Oil in the Layer Based on Heterogeneity}

The macroheterogeneity of the reservoir is mainly reflected in the geometry of sand body, reservoir lithology, physical property, permeability heterogeneity, and interlayer distribution, which have different controls over the distribution of remaining oil. The main factors controlling the distribution of remaining oil in this study area are as follows.

The heterogeneity is the key factor that affects the sweep volume of vertical injection water and the distribution of remaining oil. In the positive rhythm sand body, the remaining oil is mainly distributed in the upper-middle section with low permeability and weak washing degree. In the reverse rhythm sand body, the swept volume of injected water is large, the displacement of injected water is uniform, and the upper and lower parts are all the potential areas of remaining oil. It is generally believed that water is always injected along the relatively high permeability section, resulting in high water drive degree and low remaining oil saturation.

The intraformational heterogeneity obtained by using the frequency distribution of the composite index of the pore structure calculated by the geological model data is consistent with the intraformational heterogeneity obtained by using the core data to analyze the interlayer's composite index of the pore structure. From the $\mathrm{K}_{7}{ }^{1}$ layer to $\mathrm{K}_{7}{ }^{4}$ layer, the heterogeneity in the reservoir is gradually weakened. From the oil saturation of the $\mathrm{K}_{7}^{2}$ and $\mathrm{K}_{7}^{4}$ layer (Figure 6), the displacement effect of the $\mathrm{K}_{7}^{4}$ layer is better than that of the $\mathrm{K}_{7}^{2}$ layer.

It can be seen from Table 3 that the recovery degree of the $\mathrm{K}_{7}^{4}$ layer is $19.18 \%$ and that of the $\mathrm{K}_{7}^{2}$ layer is $27.20 \%$. 


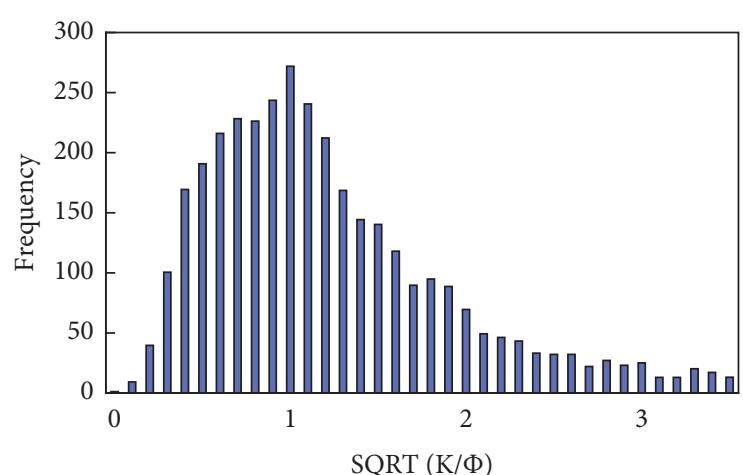

(a)

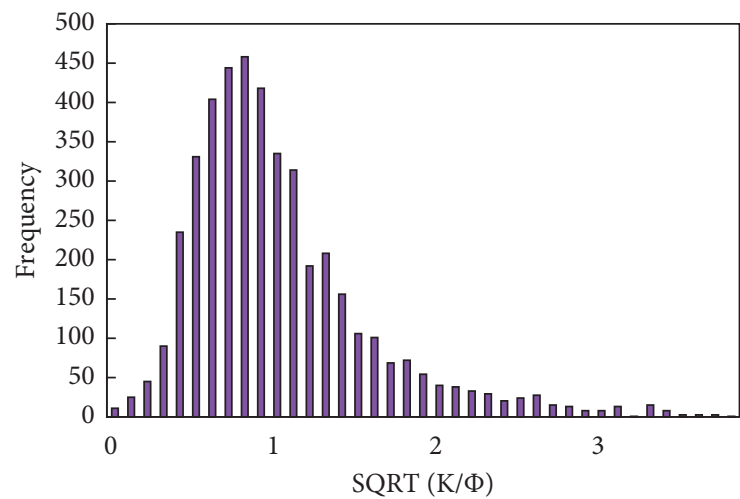

(c)

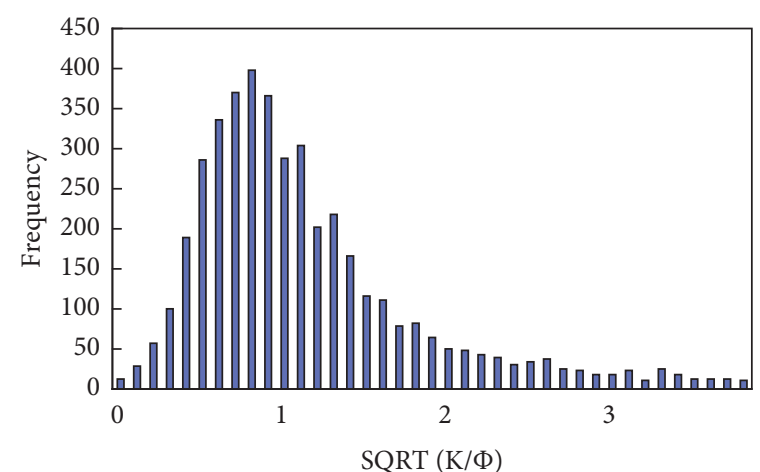

(b)

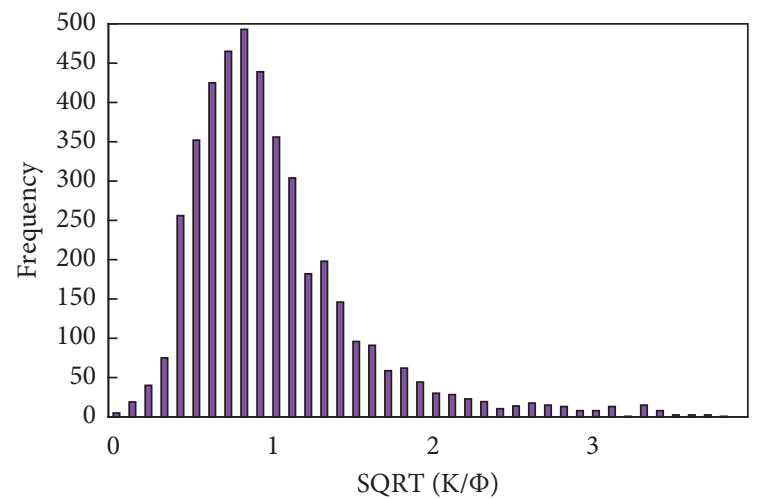

(d)

FIGURE 4: Frequency distribution of composite index of pore structure. (a) $\mathrm{K}_{7}{ }^{1}$. (b) $\mathrm{K}_{7}{ }^{2}$. (c) $\mathrm{K}_{7}{ }^{3}$. (d) $\mathrm{K}_{7}{ }^{4}$.

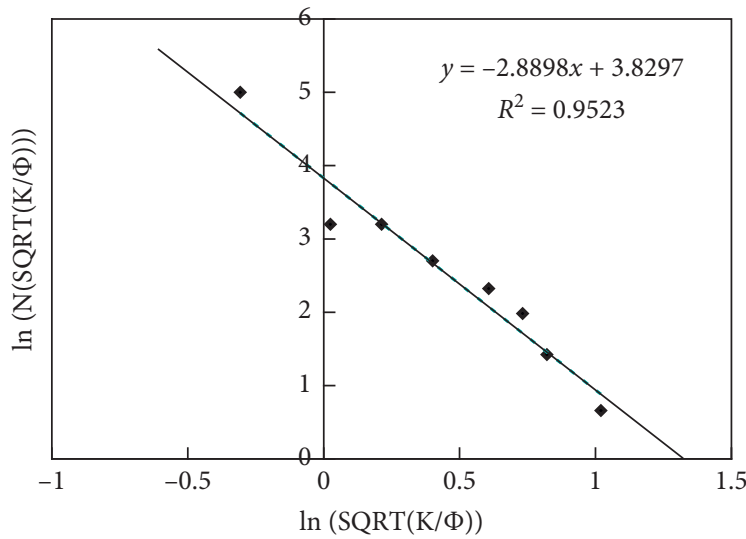

(a)

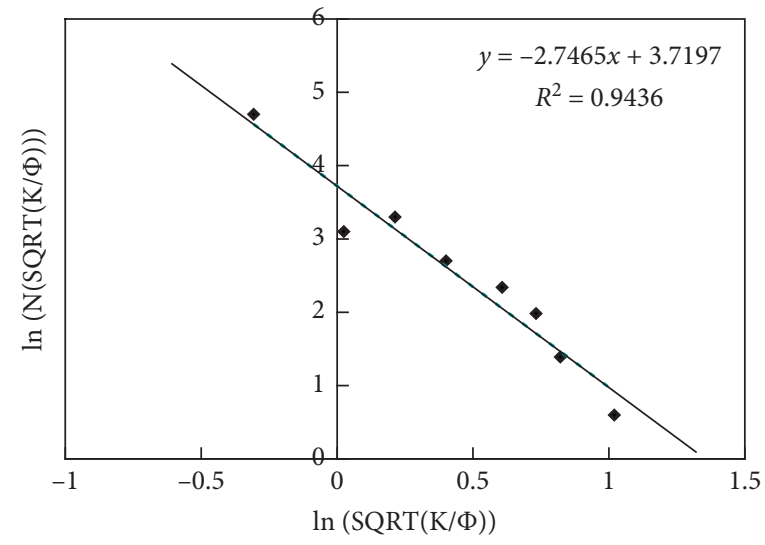

(b)

FIgure 5: Continued. 


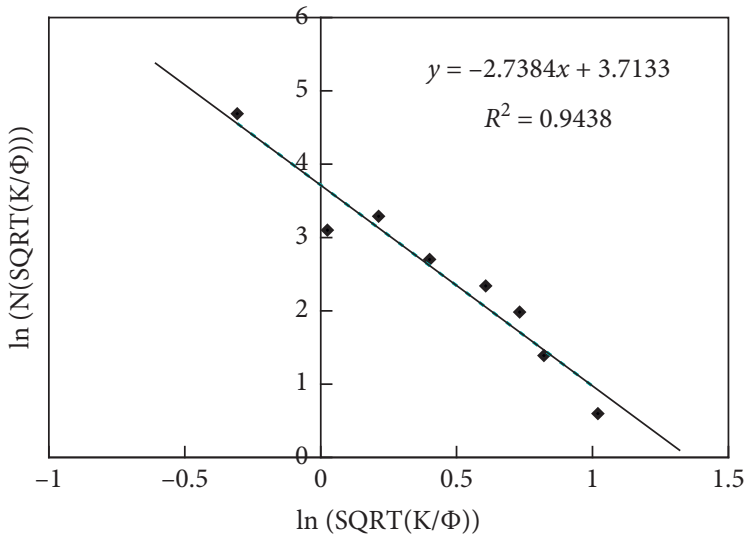

(c)

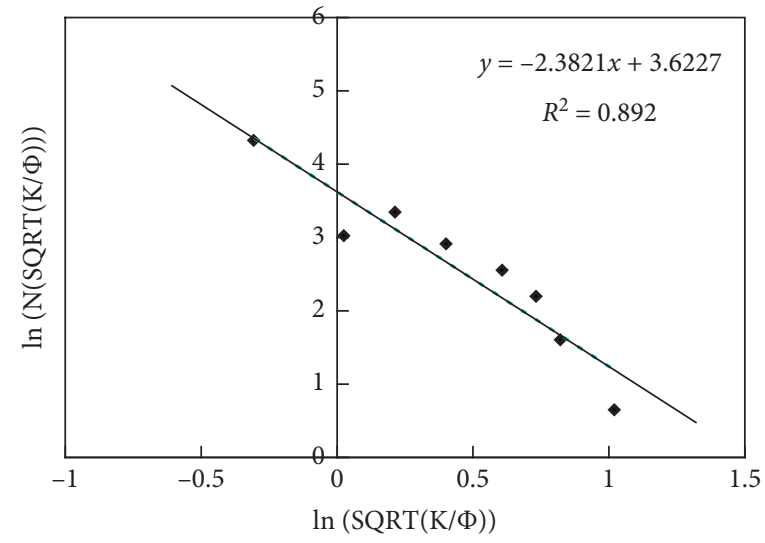

(d)

Figure 5: Fractal dimension of composite index of the pore structure. (a) $\mathrm{K}_{7}{ }^{1}$. (b) $\mathrm{K}_{7}{ }^{2}$. (c) $\mathrm{K}_{7}{ }^{3}$. (d) $\mathrm{K}_{7}^{4}$.

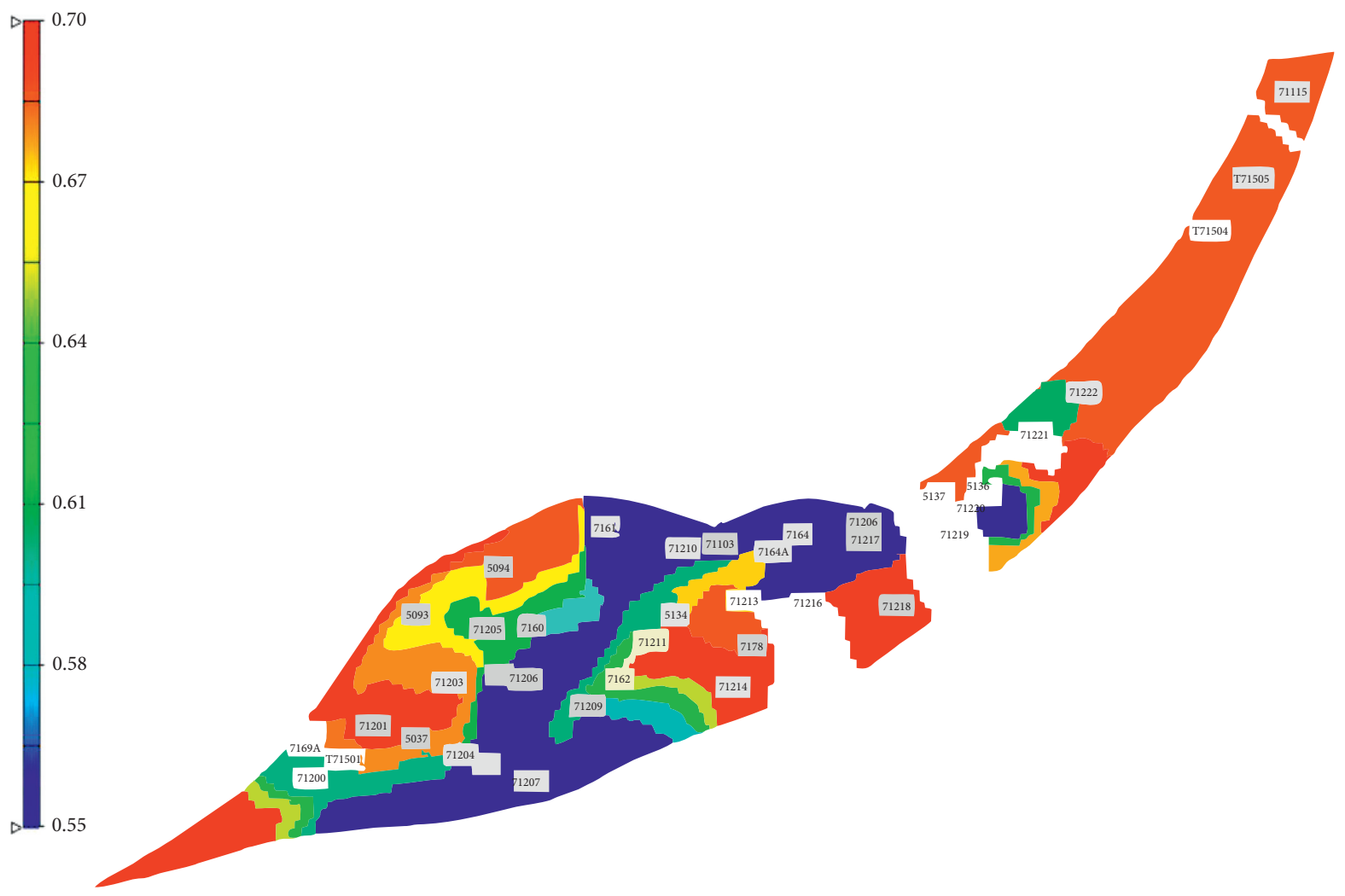

(a)

Figure 6: Continued. 


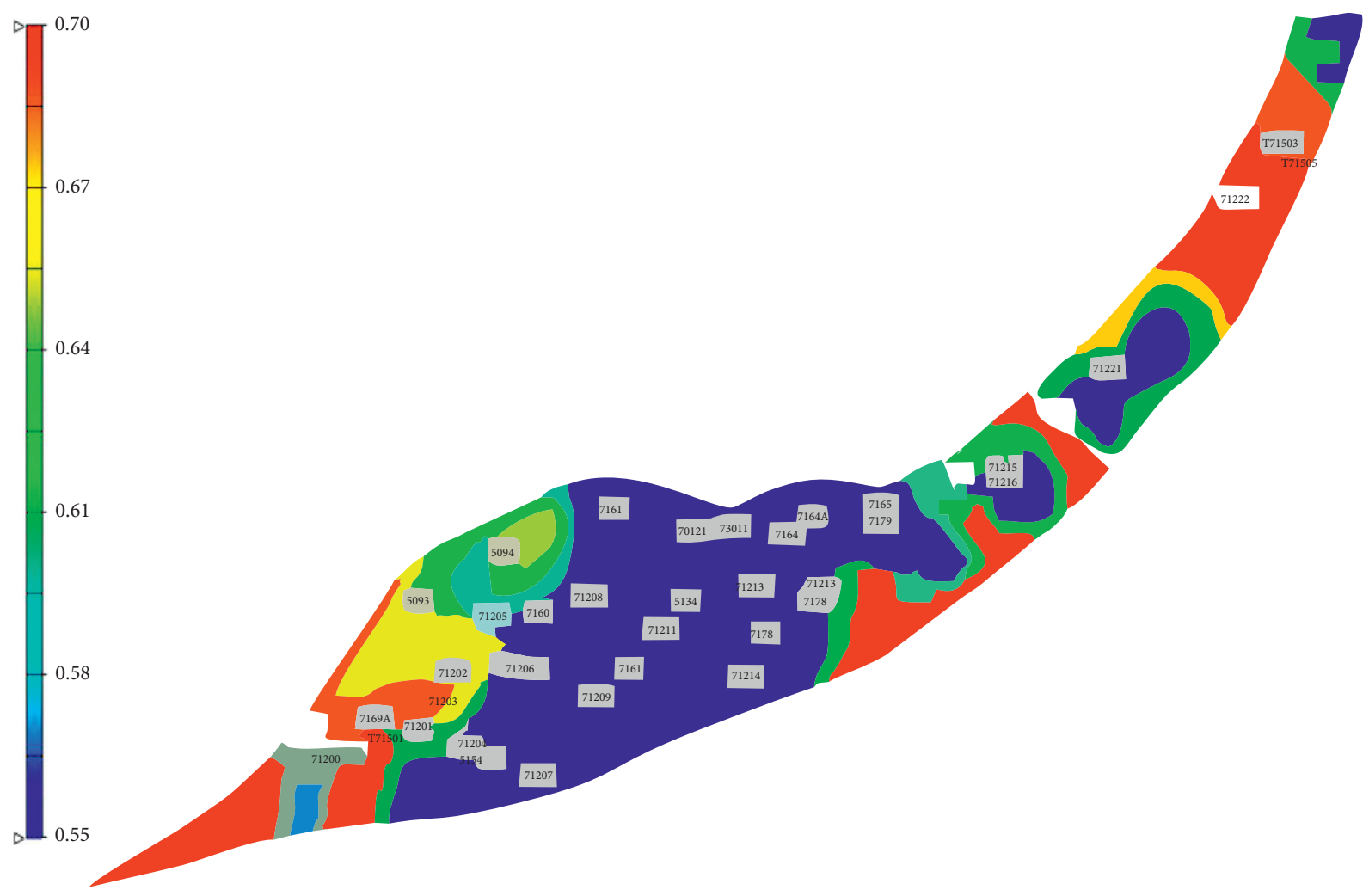

(b)

Figure 6: Oil saturation of (a) $\mathrm{K}_{7}^{2}$ and (b) $\mathrm{K}_{7}^{4}$ (at present).

TABLE 3: Statistics of crude oil recovery (at present).

\begin{tabular}{lcccc}
\hline Layer & Geological reserves $\left(10^{4} t\right)$ & $\begin{array}{c}\text { Recovery condition } \\
\text { Cumulative oil production }\left(10^{4} t\right)\end{array}$ & Recovery degree (\%) & Remaining oil volume $\left(10^{4} t\right)$ \\
\hline $\mathrm{K}_{7}{ }^{1}$ & 25.7 & 3.2434 & 12.62 & 22.46 \\
$\mathrm{~K}_{7}{ }^{2}$ & 22.1 & 6.0123 & 27.20 & 16.09 \\
$\mathrm{~K}_{7}{ }^{3}$ & 39.6 & 11.9182 & 30.10 & 27.68 \\
$\mathrm{~K}_{7}{ }^{4}$ & 28.3 & 5.4282 & 19.18 & 22.87 \\
\hline
\end{tabular}

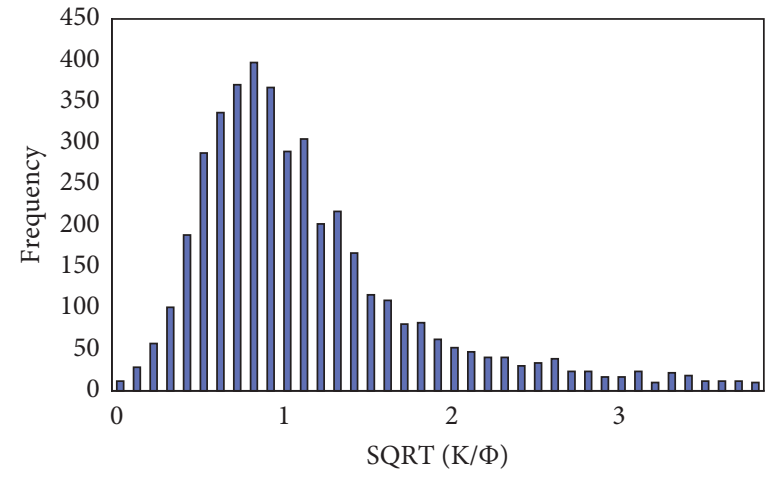

(a)

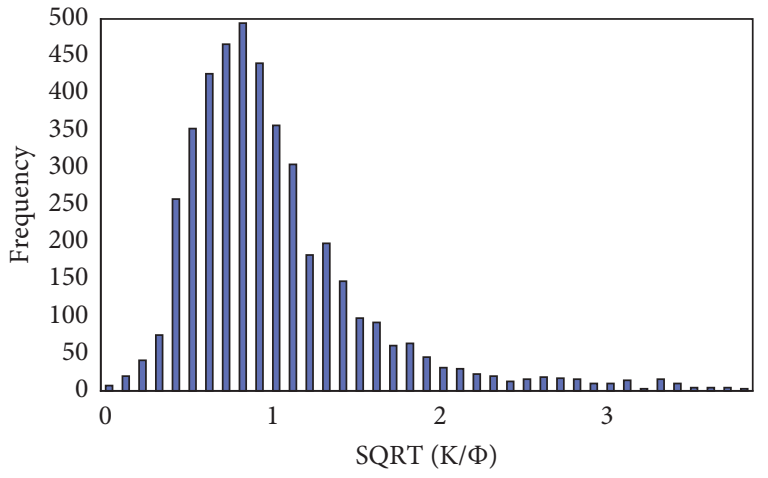

(b)

FIGURE 7: Frequency distribution of the composite index of the pore structure. (a) $\mathrm{K}_{7}^{2}$. (b) $\mathrm{K}_{7}^{4}$. 
The frequency distribution of the composite index of pore structure of $\mathrm{K}_{7}^{2}$ and $\mathrm{K}_{7}^{4}$ are shown in Figure 7 .

The displacement effect of the $\mathrm{K}_{7}{ }^{4}$ layer is better than that of the $\mathrm{K}_{7}^{2}$ layer, but the recovery degree of the $\mathrm{K}_{7}^{4}$ layer is lower than that of the $\mathrm{K}_{7}{ }^{2}$ layer. This is because, although the heterogeneity of the $\mathrm{K}_{7}{ }^{4}$ layer is weaker than that of the $\mathrm{K}_{7}{ }^{2}$ layer, the composite index of the pore structure of the $\mathrm{K}_{7}^{4}$ layer is mainly concentrated in $0.5-1.5$, while the composite index of the pore structure of the $\mathrm{K}_{7}^{2}$ layer is widely distributed in the range from $0.5-3$. The composite index of the pore structure of the $\mathrm{K}_{7}{ }^{4}$ layer is relatively smaller than the $\mathrm{K}_{7}{ }^{2}$ layer. As we know, the smaller the composite index of pore structure is, the lower the recovery degree is, so the recovery degree of $\mathrm{K}_{7}{ }^{4}$ layer is relatively smaller.

It can be seen that, in the process of oil displacement, the heterogeneity in the layer affects the distribution of remaining oil, and the remaining oil in the layer with small composite index of the pore structure will be relatively enriched. The composite index of the pore structure can be used to predict the distribution of remaining oil.

\section{Conclusions}

In this study, the composite index of the pore structure $(\mathrm{SQRT}(\mathrm{K} / \Phi))$ is introduced to study the pore microstructure of the reservoir, which can be used to quantitatively characterize the heterogeneity of the reservoir, and this parameter (SQRT $(\mathrm{K} / \Phi)$ ) can comprehensively describe the characteristics of the micropore structure well. The interlayer distribution of remaining oil can be predicted by using the composite index of the pore structure (SQRT $(K / \Phi))$, and the result is basically consistent with that calculated by the numerical simulation method. It is found that the larger the fractal dimension of the composite index of the pore structure is, the stronger the heterogeneity of reservoir is; the smaller the composite index of the pore structure is, the smaller the recovery degree is. The composite index of the pore structure can be used to analyze and predict the interlayer distribution of remaining oil, which provides a new direction for the prediction method of remaining oil, but we have to also acknowledge that our proposed composite index appears to work for the particular field, and it is not universal and may not for other formations.

In this study, $\mathrm{K}_{7}$ sand formation of an oilfield in China is taken as an example, and the composite index of the pore structure $(\operatorname{SQRT}(\mathrm{K} / \Phi))$ is used to analyze the intraformational heterogeneity and predict the distribution of remaining oil in the formation. The conclusions are

(1) The intraformational heterogeneity is related to the composite index of the pore structure. The larger the fractal dimension of the composite index of the pore structure is, the stronger the intraformational heterogeneity of the reservoir is; the smaller the fractal dimension of the composite index of the pore structure is, the weaker the intraformational heterogeneity of the reservoir is.

(2) The interlayer distribution of remaining oil can be predicted by using the composite index of pore structure (SQRT $(\mathrm{K} / \Phi)$ ), and the result is basically consistent with that calculated by the numerical simulation method. The smaller the index is, the lower the recovery degree is, and the remaining oil is also relatively richer. This also explains the abnormal phenomenon that the displacement effect of the $\mathrm{K}_{7}{ }^{4}$ layer is better, but the recovery degree is smaller.

\section{Data Availability}

The data used to support the findings of this study are available from the corresponding author upon request.

\section{Conflicts of Interest}

All authors declare that there are no conflicts of interest regarding the publication of this article.

\section{Acknowledgments}

The work was financially supported by the National Science and Technology Major Project of China (Grant no. 2017ZX05013-001).

\section{References}

[1] C. Li, X. L. Yang, and G. L. Zhadan, “Technical countermeasures for water control and oil stabilization in high watercontaining exploitation period of grit frame reservoir," Journal of Xinjiang Petroleum Institute, vol. 16, no. 3, pp. 56-59, 2004.

[2] H. Q. Tan, Q. Fu, and L. X. Li, “Application of streamline numerical simulation method to study of remaining oil distribution in high water-cut stage oilfield," Journal of Chengdu University of Technology (Science \& Technology Edition), vol. 44, no. 1, pp. 30-35, 2017.

[3] S. B. Zhang, G. M. Yao, and Z. Q. Dong, "Study on the characteristics of remaining oil saturation distribution," Fault-Block Oil \& Gas Field, vol. 7, no. 3, pp. 19-22, 2000.

[4] A. A. Al-harbi, D. P. Schmitt, and S. X. Mark-Ma, "Toward quantitative remaining oil saturation (ROS): determination challenges and techniques," in Proceedings of theSPE Annual Technical Conference and Exhibition, Denver, Colorado, USA, October 2011.

[5] Z.-z. Han, R.-c. Yang, A.-p. Fan, Q.-c. Chen, and Y.-t. Shao, "Remaining oil distribution in Ng33 bottom water reservoir of Lin 2-6 fault-block in Huimin depression and potential tapping in horizontal well," Mining Science and Technology (China), vol. 19, no. 1, pp. 102-107, 2009.

[6] J. Li, Y. Liu, Y. Gao, B. Cheng, F. Meng, and H. Xu, "Effects of microscopic pore structure heterogeneity on the distribution and morphology of remaining oil," Petroleum Exploration and Development, vol. 45, no. 6, pp. 1112-1122, 2018.

[7] K. J. Webber, "How heterogeneity affects oil recovery," in Reservoir Characterization, L. W. Lake and H. B. Carroll, Eds., pp. 487-544, Academic Press, Orlando, FL, USA, 1986.

[8] J. A. Daws and D. J. Prosser, "Scales of permeability heterogeneity within the Brent group," Journal of Petroleum Geology, vol. 15, no. 4, pp. 397-417, 1992.

[9] Y. N. Qiu and Z. Q. Chen, Reservoir Description, Petroleum Industry Press, Beijing, China, 1996.

[10] G. M. Shook and K. M. Mitchell, A Robust Measure of Heterogeneity for Ranking Earth Models: The F PHI Curve and 
Dynamic Lorenz Coefficient, Society of Petroleum Engineers, Muscat, Oman, 2009.

[11] B. Rashid, A. H. H. Muggeridge, A. Bal, and G. Williams, "Quantifying the impact of permeability heterogeneity on secondary-recovery performance," SPE Journal, vol. 17, no. 02, pp. 455-468, 2012.

[12] V. A. Torrealba, H. Hoteit, and A. Chawathe, "Improving chemical EOR simulations and reducing the subsurface uncertainty using downscaling conditioned to tracer data," in Proceedings of the SPE Annual Technical Conference and Exhibition, October 2017.

[13] H. Hoteit and A. Chawathé, Making Field-Scale Chemical EOR Simulations a Practical Reality Using Dynamic Gridding, Society of Petroleum Engineers, Muscat, Oman, 2014.

[14] H. N. Li, H. M. Xu, and N. Xu, "The heterogeneity model of low permeability reservoir and remaining oil distribution-a case study of Dujiatai oil zone in Qi 9-Huan 50 block, the west liaohe depression," Petroleum Geology \& Experiment, vol. 28, no. 4, pp. 404-408, 2006.

[15] W. Lin, S. C. Xiong, and Y. Liu, "Spontaneous imbibition in tight porous media with different wettability: pore-scale simulation," Physics of Fluids, vol. 32, no. 11, 2021.

[16] X. L. Zhao, Z. M. Yang, and W. Lin, "Study on pore structures of tight sandstone reservoirs based on nitrogen adsorption, high-pressure mercury intrusion, and rate-controlled mercury intrusion," Journal of Energy Resources Technology, vol. 141, no. 11, Article ID 112903, 2019.

[17] X. L. Zhao, Z. M. Yang, and Z. Y. Wang, "An experimental study on stress sensitivity of tight sandstones with different microfractures," Advances in Civil Engineering, vol. 2020, Article ID 1865464, 10 pages, 2020.

[18] X. Zhao, Z. Yang, W. Lin et al., "Fractal study on pore structure of tight sandstone based on full-scale map," International Journal of Oil, Gas and Coal Technology, vol. 22, no. 2, pp. 123-139, 2019.

[19] W. Lin, X. Li, Z. Yang et al., "A new improved threshold segmentation method for scanning images of reservoir rocks considering pore fractal characteristics," Fractals, vol. 26, no. 02, Article ID 1840003, 2018.

[20] W. Lin, Z. Yang, X. Li et al., "A method to select representative rock samples for digital core modeling," Fractals, vol. 25, no. 04, Article ID 1740013, 2017. 